Supporting Information for ic035132i to Inorg. Chem.

\title{
Nickel Complexes with New Bidentate P,N Phosphinito-Oxazoline and - Pyridine Ligands; Application for the Catalytic Oligomerization of Ethylene
}

\author{
Fredy Speiser, and Pierre Braunstein ${ }^{*}, \dagger$ \\ Laboratoire de Chimie de Coordination (UMR 7513 CNRS), Université Louis Pasteur, \\ 4 rue Blaise Pascal, F-67070 Strasbourg Cédex, France \\ Lucien Saussine \\ Institut Français du Pétrole, Direction Catalyse et Séparation, CEDI René Navarre, BP 3 , \\ F-69390 Vernaison, France

\section{Richard Welter} \\ Laboratoire DECMET, UMR CNRS 7513, Université Louis Pasteur, \\ 4 rue Blaise Pascal, F-67070 Strasbourg Cedex, France.
}

FIGURES. ORTEP Views of the molecular structures of complexes 14-17. Thermal ellipsoids enclose $50 \%$ of the electron density

\footnotetext{
${ }^{\dagger}$ For correspondence: E-mail: braunst@chimie.u-strasbg.fr. Fax: +33-390 241322.
} 


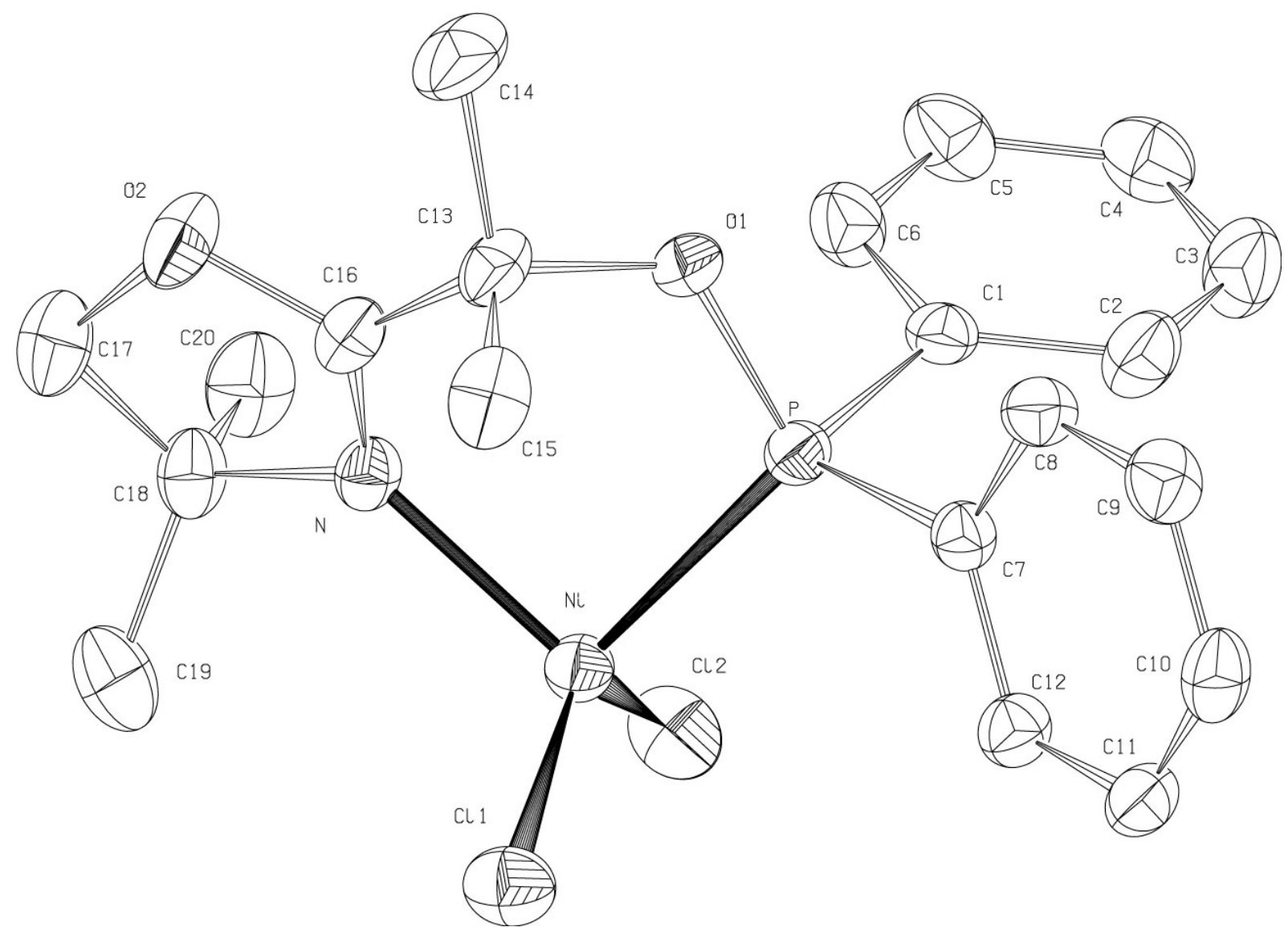

Figure 1. ORTEP view of the molecular structure of $\mathbf{1 4}$ with the complete numbering scheme. Thermal ellipsoids enclose $50 \%$ of the electron density. 


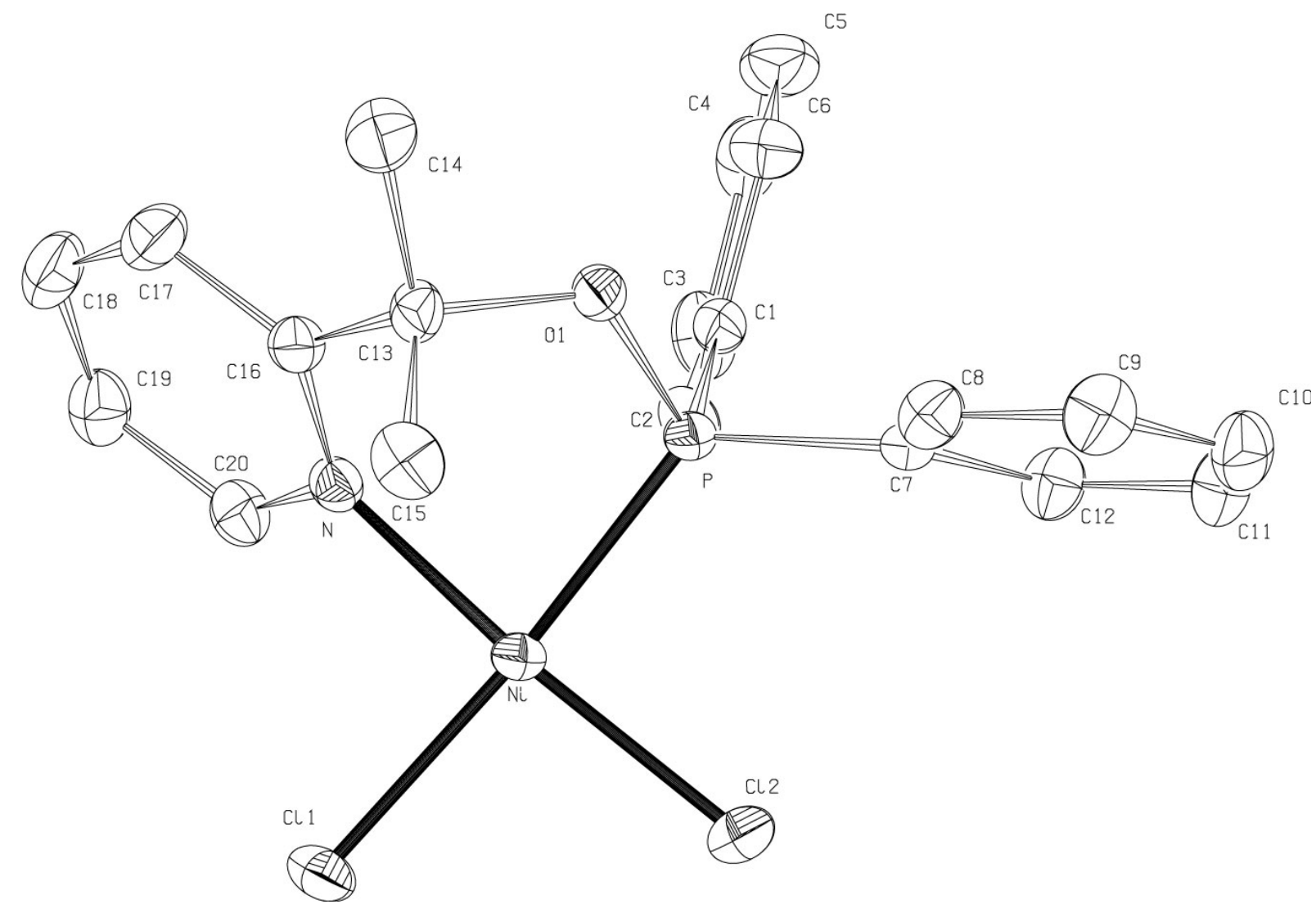

Figure 2. ORTEP view of the molecular structure of $\mathbf{1 5}$ with the complete numbering scheme. Thermal ellipsoids enclose $50 \%$ of the electron density. 


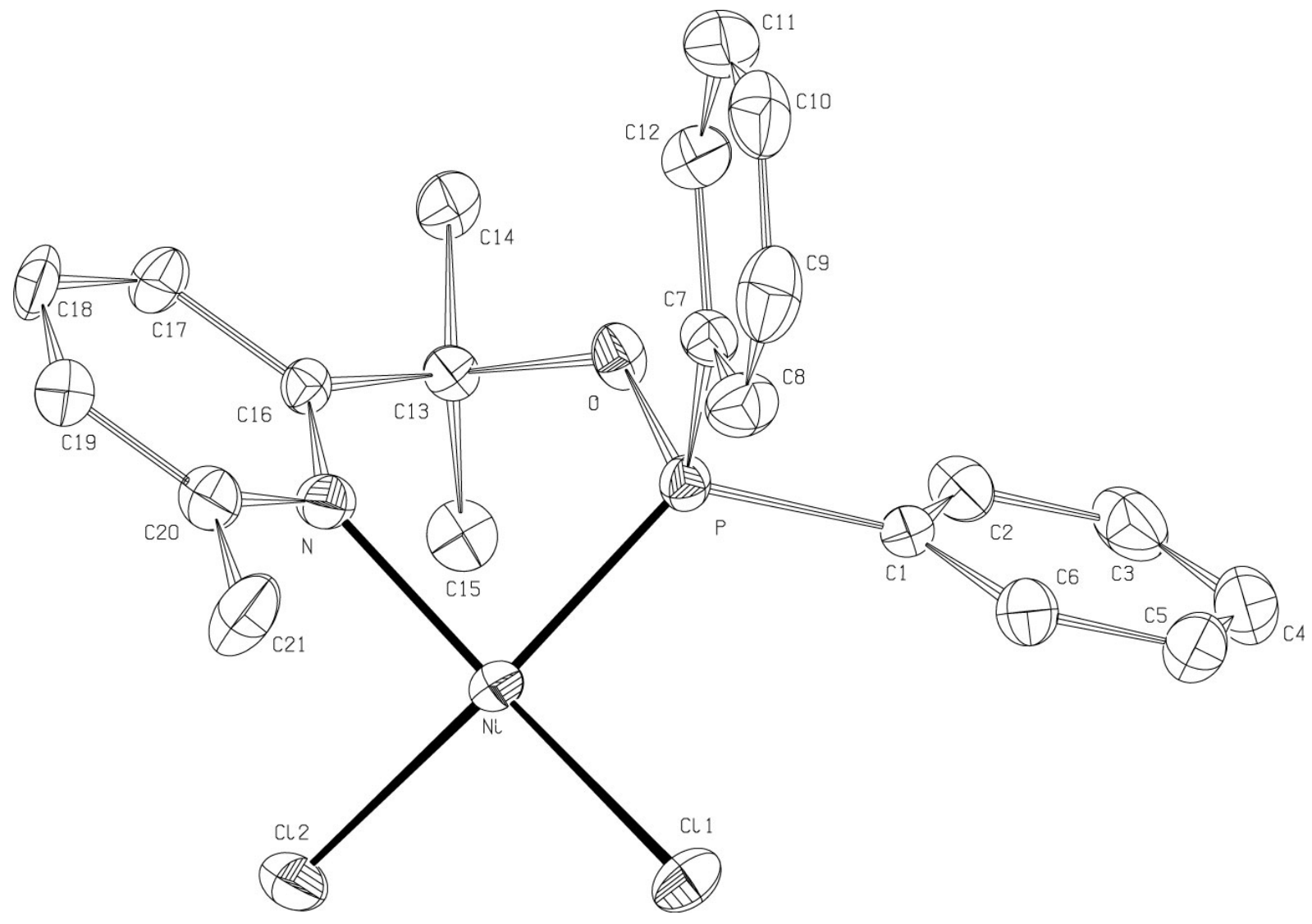

Figure 3. ORTEP view of the molecular structure of $\mathbf{1 6}$ with the complete numbering scheme. Thermal ellipsoids enclose $50 \%$ of the electron density. 


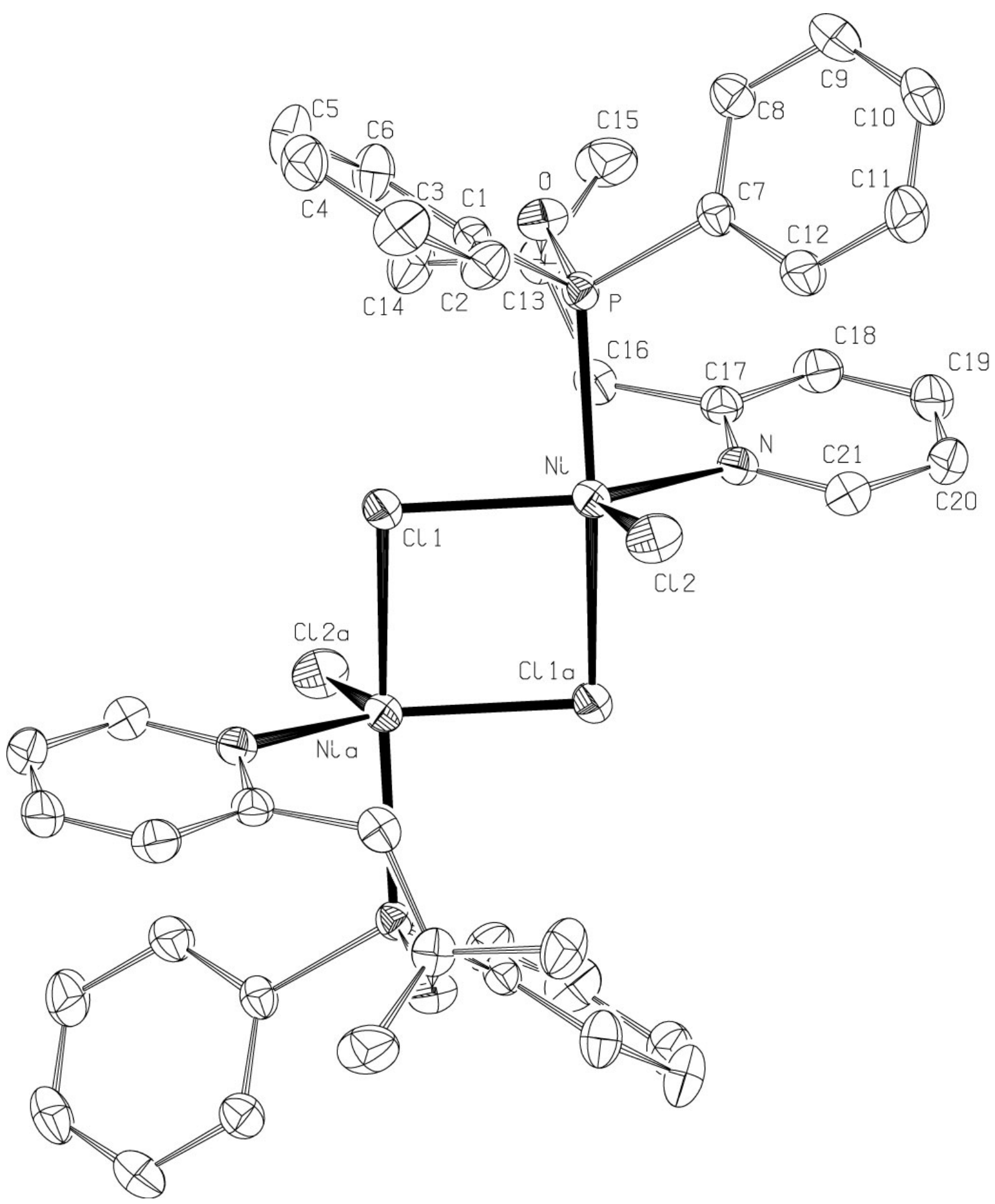

Figure 4. ORTEP view of the molecular structure of $\mathbf{1 7}$ with the complete numbering scheme. Thermal ellipsoids enclose $50 \%$ of the electron density. 